In evaluating injury in children, child protection paediatricians are tasked with determining whether the history given by parents or caregivers is valid with respect to explaining injury causation. This presentation summarises metacognition and in particular the dual processing theory of "fast and slow thinking" to explain how complex information in contexts of uncertainty is processed to produce decisions and responses, applied to a child protection context. An example is used that resembles abusive head trauma which focuses on understanding the difference between likelihood and plausibility in forensic interpretations of injury causation.

\section{ELDERLY SEXUAL ASSAULT}

\author{
$\underline{\text { Gregory Dayman }}$ \\ Yarrow Place, Womens and Childrens Hospital, Adelaide, SA, \\ Australia
}

Presentations of sexual assault in women and men aged 60 years and over are infrequent occurrences for both sexual assault medicine services and the forensic pathologist. Complainants range from fit, competent adults to the severely disabled, nonverbal and frail elderly. The forensic examination of these complainants can be challenging due to lack of competency to consent or provide history of the assault. The frail elderly victim may be unable to cooperate with the physical and anogenital examinations. Fragility of the ageing integument and the lack of oestrogenisation of the menopausal female genital tract increase the risk of injury from sexual trauma. The presence of co-morbid medical conditions can be confused with trauma. Rapid death following sexual assault in the geriatric victim is the result of mechanisms seen in sexual assault generally including strangulation and head trauma however can also be the result of severe anogenital injury. An understanding of co-morbid medical conditions occurring in geriatric anogenital tissues and the use of histology at autopsy can avoid misdiagnosis.

\section{TOXICOLOGY FROM A FORENSIC PHYSICIAN'S PERSPECTIVE AND HOW RECENT CHANGES IN THE STANDARDS MAY AFFECT YOU}

\author{
John A. M. Gall ${ }^{1,2,3}$ \\ ${ }^{1}$ Department of Paediatrics, The University of Melbourne, Vic, \\ Australia; ${ }^{2}$ Victorian Forensic Paediatric Medical Service, \\ Royal Children's Hospital and Monash Medical Centre, \\ Melbourne, Vic, Australia; and ${ }^{3}$ Era Health, Melbourne, Vic, \\ Australia
}

There are three Australian Standards that may have an impact upon forensic physicians in relation to their involvement with drug and alcohol testing. These are AS/NZS 4308:2003 Procedures for specimen collection and the detection and quantification of drugs of abuse in urine, AS/NZS 4760:2019 Procedure for specimen collection and the detection and quantification of drugs in oral fluid, and AS/NZS 3547:2019 Breath alcohol testing devices. The first two deal with the testing of specimens (urine and oral fluids) for medico-legal, workplace and court- directed purposes and cover the collection, on-site screening, and handling and dispatch of specimens to a laboratory for screening and/or confirmatory testing. The latter specifies requirements for the performance, testing and marking of breath alcohol testing devices for uses including personal, workplace and medical screening purposes. AS/NZS 4308:2003 is currently in the process of revision and the new Standard may be expected in 2022. The content of these three Standards will be discussed in relation to their implication for forensic physicians.

\section{NON-FATAL STRANGULATION AND THE GOLD COAST FORENSIC MEDICINE CLINICAL AND LEGAL EXPERIENCE}

$\underline{\text { Danika Fietz }}$

Forensic Medicine, Emergency Department, Gold Coast Hospital \& Health Service, Qld, Australia

Non-fatal strangulation (NFS) is considered an insidious form of domestic violence. In at least $50 \%$ of cases, strangulation leaves no obvious signs of injury and a proportion of NFS cases are minimised or go unreported. ${ }^{1-3}$ While they are rare overall, neck artery dissections are one of the most lethal and overlooked outcomes of strangulation and the most common cause of stroke in young people. ${ }^{4}$

A retrospective review study based on patients reporting NFS attending the Gold Coast Hospitals who were then referred for clinical forensic examinations during October 2018 to October $2020(n=66)$ revealed that $73 \%$ were offered medical imaging and of those who underwent medical imaging, $11 \%$ were confirmed to have internal injuries. Of these, $7 \%$ had neck artery dissections. This represents one neck artery dissection for every $15 \mathrm{CT} / \mathrm{MR}$ angiograms.

It remains unclear in the literature which patients should be medically imaged post NFS. The current review, albeit small, revealed that symptoms and signs such as neck tenderness or pain and/or neck bruising were present in all of those who were confirmed to have internal injuries.

This presentation will include comment on the role of medical evidence in NFS cases to date where possible.

\section{References}

1. Pritchard A, Reckdenwald A, Nordham C. Nonfatal strangulation as part of domestic violence: a review of research. Trauma Violence Abuse 2015; 18: 407-24.

2. Strack G, McClane G, Hawley D. A review of 300 attempted strangulation cases. Part I: criminal legal issues. J Emerg Med 2001; 21: 303-9.

3. Douglas H, Fitzgerald R. Strangulation, domestic violence and the legal response. Sydney Law Rev 2014; 36: 231-54.

4. UpToDate. Spontaneous and cervical artery dissection: clinical features and diagnosis. Mar 2019; cited 25 Oct 2020. https://www.uptodate.com/contents/spontaneous-cerebraland-cervical-artery-dissection-clinical-features-anddiagnosis?search=traumatic/cervical/artery/dissection \& source=search_result\&selectedTitle $=1 \sim 150 \&$ usage type=default\&display_rank=1\#H95541785 